\title{
The role of signaled periods of nonreinforcement in responding on a random schedule in autoshaping
}

\author{
STEVEN J. ROBBINS and ROBERT A. RESCORLA \\ University of Pennsylvania, Philadelphia, Pennsylvania
}

\begin{abstract}
Little responding develops to a conditioned stimulus (CS) that is placed in a random relation to an unconditioned stimulus (US). However, if the USs not preceded by that CS are themselves signaled by another stimulus, then the CS does come to elicit responding. This result has been attributed (e.g., by Durlach, 1983) to the signal's blocking of conditioning to background cues that otherwise would prevent conditioning of the CS. However, Goddard and Jenkins (1987) have suggested the alternative that signaling the USs promotes responding due to the adventitious creation of periods of signaled nonreinforcement. Two experiments were conducted to assess this alternative, involving an autoshaping preparation in pigeons. In Experiment 1, little responding to a keylight CS presented in a random relation to a food US occurred, despite the explicit presentation of a discrete noise signaling periods of no food in the intertrial interval (ITI). Experiment 2 was designed to replicate the procedure of Goddard and Jenkins, in which an auditory stimulus extended throughout the ITI of a random schedule, terminating only prior to extra USs and during the CS. Contrary to their findings, little responding developed to the target CS. However, responding did develop when the sound-free period occurred only prior to the extra USs. These results offer little support for the hypothesis that signaled periods of nonreinforcement promote responding on random schedules. However, they are consistent with the view that signaling of ITI USs acts by preventing conditioning of potentially competitive background cues.
\end{abstract}

The role of contingency in producing an association between a conditioned stimulus (CS) and an unconditioned stimulus (US) has recently received much attention. Of particular interest have been the results of training in which the probability of occurrence of the US is equal in the presence and absence of the CS. Such random training has been found to generate little or no responding to the CS (e.g., see Durlach, 1983; Dweck \& Wagner, 1970; Gamzu \& Williams, 1973; Rescorla, 1968, 1972; but see also Ayres, Benedict, \& Witcher, 1975). Two general classes of models have been advanced to account for this result, both of which stress the importance of associations formed between contextual stimuli present during training and the US. One class of models postulates that such context-US associations serve to attenuate learning about the CS-US pairings provided (e.g., see Mackintosh, 1975; Rescorla \& Wagner, 1972). The other class of models postulates that learning about the CS is unaffected, but that performance to the CS is impaired by a highly valued context (e.g., see Gibbon \& Balsam, 1981; Jenkins, Barnes, \& Barrera, 1981; Miller \& Schachtman, 1985).

The learning model of Rescorla and Wagner, for example, postulates that copresent stimuli compete for a

This research was supported by National Science Foundation Gran BNS 83-08176 to Robert A. Rescorla. Portions of the research were completed during Steven J. Robbins's tenure as a National Science Foundation predoctoral fellow. Reprint requests should be sent to etther author at the Department of Psychology, University of Pennsylvania, 3815 Walnut Street, Philadelphia, PA 19104. limited amount of associative strength supported by the US. In this view, the context in a random training schedule successfully competes with the CS for associative strength, thereby preventing the development of responding to the CS. The extra USs provided in the absence of a CS in the random schedule result in a strong contextUS association, and this association serves to block learning about the CS.

By contrast, the performance model of Gibbon and Balsam (1981) postulates that learning about CS-US and context-US pairings goes on independently, but that performance to the CS is determined by the ratio of CS strength to context strength. When this ratio is sufficiently high, responding results. In the case of the random schedule, little responding is observed, since the value of this ratio approaches one.

One situation in which the two classes of models make clearly different predictions involves providing a discrete signal for the unpaired USs occurring in a random schedule. According to the Rescorla-Wagner model, such a signal should successfully compete with the context for associative strength and hence attenuate the context's value. A less excitatory context should in turn permit the development of responding to the target CS. The GibbonBalsam model makes no such prediction, since concurrently presented stimuli gain associative strength independently. Consequently, signaling the extra USs in a random design should affect neither the associative strength of the context nor its ability to block performance to the CS. 
Several recent autoshaping experiments have collected data that are inconsistent with the predictions of performance models. For example, Durlach (1983) demonstrated that acquisition of responding to a target CS presented in a random schedule occurs when the extra USs are preceded by a discrete signal, but not when those USs are unsignaled. Similar results were obtained by Goddard and Jenkins (1987). Such data suggest that the observed lack of responding to a target CS on a random schedule is due to competition from the context for associative strength as envisioned by the Rescorla-Wagner model.

Goddard and Jenkins (1987) argued, however, that blocking of context conditioning is not the only possible mechanism by which signaling extra USs could promote responding to the target CS. They noted that providing a discrete signal for the unpaired USs in a random design also has the effect of establishing the context alone as a period of guaranteed nonreinforcement. Therefore, it may be the establishment of such periods of signaled nonreinforcement that is crucial for responding to the target CS to develop, possibly as the result of a contrast effect. A related proposal was advanced by Jenkins and Lambos (1983) and by Brandon (1984), in describing the circumstances under which an already excitatory stimulus loses its power to evoke a response in a random schedule. They suggested that contrasting periods of signaled nonreinforcement are required for maintenance of conditioned responding during random training.

The two experiments reported here represent an attempt to evaluate the general notion that signaled periods of nonreinforcement should promote responding to a novel CS trained in a random relation to the US. Both studies employed an autoshaping procedure with pigeons. In Experiment 1 , we assessed whether acquisition of responding to a target CS on a random schedule occurs when a discrete signal of nonreinforcement is explicitly provided at intervals during the ITI. In Experiment 2, we looked more specifically at whether responding will develop when contrast periods of nonreinforcement are provided adjacent in time to the target CS. To this end, in Experiment 2 we employed a procedure first investigated by Goddard and Jenkins (1987), in which an auditory stimulus is provided continuously throughout nonreinforced periods of the ITI.

\section{EXPERIMENT 1}

If signaling the extra USs in a random design promotes responding to the target CS by incidentally creating a period of signaled nonreinforcement, then explicitly providing such a signal of nonreinforcement should also produce responding. In Experiment 1, this possibility was tested. Three groups of birds received identical reinforcement schedules with a target CS. All three groups also received USs in the absence of the CS at a rate sufficient to reduce the CS-US contingency to zero. Group Unsignaled received no additional events. Group Signaled experienced a diffuse auditory signal (white noise) immedi- ately preceding each of the extra USs. These two groups correspond, respectively, to the unsignaled and signaled groups studied by Durlach (1983) and Goddard and Jenkins (1987). Of most interest for the present study, Group Unpaired experienced the same number of white noise presentations as did Group Signaled, but in an explicitly unpaired relation with the US.

If signaling a period of nonreinforcement is the critical element in promoting responding, then both Group Signaled and Group Unpaired should have responded to the keylight. In Group Signaled, the noise's paired relation with the ITI USs established the context alone as a signal of nonreinforcement; in Group Unpaired, the noise's explicitly unpaired relation to the USs established the noise as such a signal. However, if preventing blocking by the context is the critical element, only Group Signaled should have responded to the keylight. In that group, the presentation of the noise prevented conditioning of background stimuli that are copresent with the target CS. In Group Unpaired, the presentation of the noise allowed those background stimuli to become conditioned and still block conditioning of the target CS.

\section{Method}

Subjects and Apparatus. The subjects were 31 experimentally naive one-year-old White Carneau female pigeons obtained from Palmetto Pigeon Plant. They were housed in pairs on a 16:8-h light:dark cycle with free access to water and grit and fed enough Purina Pigeon Grain to maintain them at $80 \%$ of their ad lib weight.

Training took place in eight identical operant chambers measuring $27 \times 27 \times 35 \mathrm{~cm}$. The metal front panel of each box had a $5 \times 5 \mathrm{~cm}$ food magazine located in its center, $5 \mathrm{~cm}$ above the wire mesh floor. Three response keys, each $2.5 \mathrm{~cm}$ in diameter, were arranged horizontally with their lower edges $20 \mathrm{~cm}$ above the floor. The middle key was located directly above the hopper, with the two other keys spaced $5 \mathrm{~cm}$ away on either side (measuring between the centers of the keys). Only the left-hand key was used in Experiment 1. Behind this key was located an IEE in-line projector, which permitted illumination of the key with two stimuli, blue (B) and an $\mathrm{X}$. The blue light illuminated the entire key, whereas the $\mathrm{X}$ consisted of two 1-mm black lines crossing at the center of a white background. The stimuli were generated by a Kodak Ektachrome slide made by photographing appropriate colors from Coloraid artist's paper.

The other three walls of the chamber were composed of clear Plexiglas. The chambers were contained within sound- and lightattenuating boxes equipped with ventilation fans providing a background noise level of about $62 \mathrm{~dB}$ re $20 \mu \mathrm{N} / \mathrm{m}$ (SPL). Mounted on the rear wall of each chamber was a 6-W bulb that was illuminated throughout the experimental session, except during operation of the food magazine. Operation of the magazine provided access to $\mathrm{Pu}$ rina Pigeon Grain and illuminated a 6-W bulb located within the hopper. Diffuse stimuli consisted of either an 80-dB white noise (N) emitted by a speaker mounted just behind the conditioning chamber or twice per second interruptions of the 6-W house light (L).

Procedure. The subjects were first trained to eat from the food magazine. The birds were initially placed in a chamber with grain already available in the hopper. Once they had begun eating, the food hopper was turned off briefly and turned on again. Over time, food presentations became progressively shorter and more widely spaced until the birds were observed to be reliably eating during magazine durations of $5 \mathrm{sec}$, spaced about 1-min apart. On each of the next 2 days, the birds were given 445 -sec hopper presentations at a mean rate of 1 per min. 
All birds were then given 16 days of autoshaping training with the $B$ stimulus. On each of the first 8 days, the birds received 20 $10-\mathrm{sec} B$ presentations, each terminating in a 5 -sec food presentation $(+)$. On the next 8 days, only half of the B presentations were reinforced. The intertrial interval (ITI) was variable around a mean of $1 \mathrm{~min}$. The birds were then assigned to the three treatment groups matched for rates of responding to the B keylight.

The birds next received 16 days of pretraining designed to give the diffuse stimulus $\mathrm{N}$ the signaling properties it would be assigned in the main training phase. All birds received discrimination training with the $\mathrm{N}$ and $\mathrm{L}$ stimuli. For the birds in Group Signaled $(n=10), 20 \mathrm{~N}+$ and $20 \mathrm{~L}$ - trials were given on each day. This contingency was reversed for the birds in Group Unpaired $(n=10)$, which received $20 \mathrm{~N}-$ and $20 \mathrm{~L}+$ presentations. Six subjects in Group Unsignaled $(n=11)$ received $20 \mathrm{~N}-$ and $20 \mathrm{~L}+$, while the remaining 5 received the reverse arrangement. For all birds, both stimuli were $10 \mathrm{sec}$ in duration and trials were presented on an ITI of mean $1 \mathrm{~min}$. In this way, the noise was trained as a signal of reinforcement in Group Signaled and as a signal of nonreinforcement in Group Unpaired, while half the birds in Group Unsignaled received each arrangement. In addition, all three groups experienced an identical number of stimuli and reinforcers during the pretranning phase.

Following pretraining, all birds received 28 days of conditioning with a random training schedule, constructed after the manner of Durlach (1983). Each 20-min session was viewed as divided into 8015 -sec intervals. Twelve of these intervals were randomly chosed to contain an $\mathrm{X}$ in the first $10 \mathrm{sec}$, and 3 of these 12 intervals contained a reinforcement in the last $5 \mathrm{sec}$. Of the remaining $68 \mathrm{inter}$ vals, 17 were chosen to contain a food presentation in the last $5 \mathrm{sec}$. The schedule was constrained so that no 2 consecutive 15 -sec intervals could contain events. In this way, the birds received a schedule in which $25 \%$ of all 15 -sec intervals were reinforced; the rate of reinforcement did not differ as a function of whether an interval contained a CS presentation. For Group Unsignaled, no additional events were programmed. For Group Signaled, each of the 17 extra USs was signaled by a $10-\mathrm{sec}$ noise presentation. For Group Unpaired, 1710 -sec noise presentations were added, but with the constraint that no other event could occur within the 5 sec preceding or following the auditory stimulus.

\section{Results and Discussion}

Initial acquisition of responding to the B keylight occurred uneventfully, and the birds pecked on $83 \%$ of all trials on the last day of pretraining. Results of the main training phase are shown in Figure 1, which depicts mean percent trials with a response for each of the three groups. In agreement with the results reported by Durlach (1983), the birds in Group Signaled quickly acquired keypecking, while those in Group Unsignaled exhibited no development of responding. Of most interest for the present study, however, is the observation that the birds in Group Unpaired showed no sign of acquiring responding over training sessions. By the fourth block of training, the birds in Group Signaled responded reliably more than the birds in both Group Unsignaled [Mann-Whitney $U(10,11)=$ $18.5, p<.05]$ and Group Unpaired $[U(10,10)=6.5$, $p<.01\}$. Responding in Groups Unsignaled and Unpaired did not differ $[U(10,11)=42, p>.05]$. This pattern persisted throughout the remainder of training, and on the last block of training Group Signaled responded reliably more than both Group Unsignaled $[U(10,11)=18, p<$ $.01]$ and Group Unpaired $[U(10,10)=15, p<.01]$.

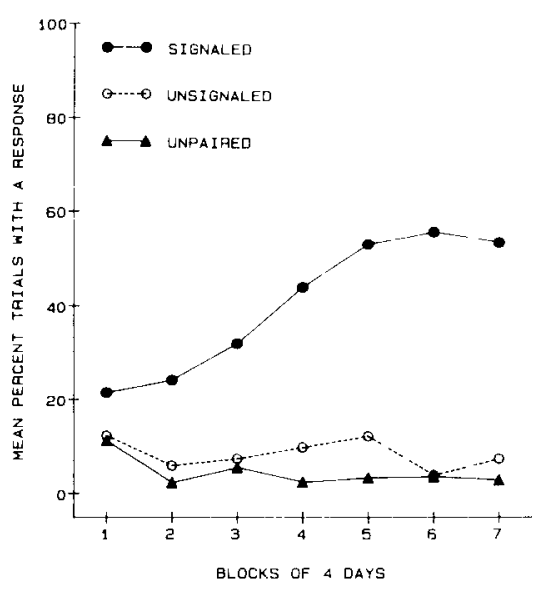

Figure 1. Mean percent of trials with a response during training in Experiment 1. Responding is shown during a keylight conditioned stimulus (CS) when non-CS foods were presented in a signaled, unpaired, or unsignaled relation to a noise stimulus.

Groups Unsignaled and Unpaired continued not to differ $[U(10,11)=47.5, p>.05]$.

One way to view the schedule used in training Group Unpaired is as a control procedure for the nonassociative effects of presenting the noise during a random schedule. On the basis of available data, it is possible that arranging for the noise to signal the ITI USs is not necessary for its faciliatory effect. Presentations of a second stimulus at any time during a random training session may be sufficient to promote acquisition to a keylight CS. The results of Group Unpaired, however, demonstrate that providing an auditory cue in a negative relationship with extra USs does not permit responding to the randomly trained keylight to develop.

Of more direct interest, however, is that the present results suggest that periods of signaled nonreinforcement are not alone sufficient to induce responding to a CS embedded in a random schedule of reinforcement. No acquisition occurred in Group Unpaired, despite the signaling of nonreinforcement with the same stimulus as was used to effectively signal extra foods in Group Signaled. Durlach (in press) has recently described an essentially similar result.

Although a period of nonreinforcement was signaled both by the white noise in Group Unpaired and by its absence in Group Signaled, one may neverthless question the equivalence of these two signals. The signal of nonreinforcement in Group Unpaired was substantially shorter than that in Group Signaled, occupying only discrete 10 -sec periods rather than the entire ITI. Moreover, that signal was presented randomly in the ITI for Group Unpaired but was assured to be adjacent to the target CS in Group Signaled. Although proposals about the mechanisms of action for signaling periods of nonreinforcement have not been specified in detail, the local contrast interpretation advanced by Jenkins and Lambos (1983) suggests that adjacency may be of importance. Consequently, 
Experiment 2 was designed to assess the importance of signaling an extended period of nonreinforcement that was adjacent to the CS.

\section{EXPERIMENT 2}

The notion that providing an explicit stimulus throughout nonreinforced periods of a random schedule might promote responding to the target CS was first explored by Goddard and Jenkins (1987). In their autoshaping study, several groups of birds received the same random relation between keylights and food as in Experiment 1 above. However, for one group of birds, a tone was present throughout the session, except for during 10-sec periods preceding reinforcement and during the 10-sec CS. That group, whose treatment is illustrated in the top panel of Figure 2, acquired responding to the target keylight as successfully as did a group whose tone signaled the extra foods. Goddard and Jenkins took this result as evidence that the critical factor in inducing responding to a stimulus on a random schedule is the creation of periods of signaled nonreinforcement, rather than the prevention of conditioning of background cues.

However, inspection of the stimulus relations used by Goddard and Jenkins reveals them to be quite like those of a standard blocking design. The termination of the auditory stimulus (A) regularly precedes all USs. As a result, the tone-free periods would be expected to acquire substantial associative strength. Since the tone-free period is also present on all those keylight CS trials that end in food, it should block conditioning of the target keylight CS. Indeed, the tone-free period is followed by food on all of its separate occasions, but only on $25 \%$ of its presentations in compound with the CS. Consequently, one might expect the CS to signal that reduction in reinforcement rate and hence become an inhibitor.

These observations make it all the more surprising that Goddard and Jenkins observed substantial responding to
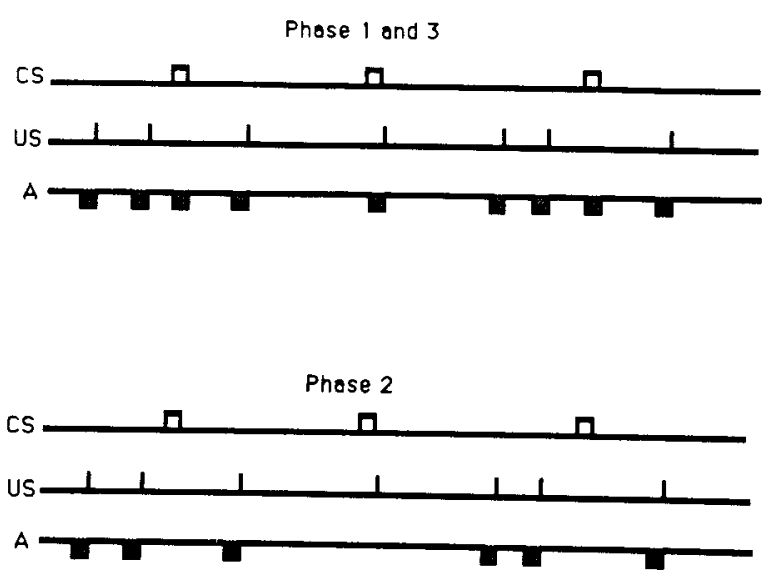

Figure 2. Design of Experiment 2. Open boxes represent presentations of a keylight conditioned stimulus (CS), vertical marks presentations of food unconditioned stimulus (US), and shaded boxes the absence of the auditory stimulus (A). the CS. Consequently, Experiment 2 was designed to replicate this result and to explore further its determinants through two procedural modifications.

First, an attempt was made to increase the salience of the sound-free signal of reinforcement. To this end, a white noise stimulus was used as the auditory stimulus in the present study rather than a tone, because previous studies in our laboratory have shown the white noise to be more salient. In addition, the amount of noise-free time provided prior to reinforcement and during CS presentations was varied. Some birds were trained with the schedule of signaled nonreinforcement provided by Goddard and Jenkins, while others received 20 -sec noise-free periods prior to reinforcement and overlapping the 10-sec CS. If one assumes that the termination of an auditory cue is not a highly salient event, then providing that termination concurrently with the onset of the keylight may severely attenuate attention to an already weak stimulus. Arranging for the noise termination to occur prior to CS onset would increase its salience on compound trials and hence its ability to block the keylight.

Second, following administration of the Goddard and Jenkins training schedule, all birds were switched to a schedule in which the noise-off stimulus was deleted during the target CS. As a result, the noise-off stimulus now occurred only prior to extra USs, as is depicted in the bottom panel of Figure 2. According to competition models of learning (e.g., see Mackintosh, 1975; Rescorla \& Wagner, 1972), this manipulation should prevent the noise-free periods from further blocking conditioning to the CS, and responding to the keylight should develop. According to a signaled nonreinforcement account, however, the signal for nonreinforcement (noise) now receives reinforcement on some occasions when it co-occurs with a target CS. Consequently, the noise is no longer as valid a signal of nonreinforcement as in Phase 1 and responding to the keylight should decrease. Following this training, all birds were returned to the original training schedule (Phase 1) in which the noise-free period occurred both prior to reinforcement and during the CS. In this way, birds were placed in an ABA design for which a signaled nonreinforcement model predicts maximum responding in the A segments and reduced responding in the B segment, while a model stressing competition between copresent cues predicts the opposite pattern.

\section{Method}

Subjects and Apparatus. The subjects were 161 -year-old White Carneau female pigeons obtained from Palmetto Pigeon Plant. These birds had a history of autoshaping training with visual stimuli other than those used in the present study. In particular, they had undergone previous conditioning with color and line-orientation stimuli projected on one half of the key. They had no prior experience with auditory stimuli. The birds were housed and fed as in Experiment 1. The apparatus from Experiment 1 was employed here. The stimuli were the white noise $(\mathrm{N})$ and the $\mathrm{X}$ keylight (projected over the entire key).

Procedure. Since these birds had previously been autoshaped with other stimuli, no magazine training was necessary. They were initially given the pretraining with the $\mathrm{N}$ stimulus that Goddard and 
Jenkins employed. On each of 15 days, the birds received 10 nonreinforced presentations of a $10-\mathrm{sec} \mathrm{N}$ stimulus. In addition, $105-$ sec food presentations were presented during the session. The termination of each $\mathrm{N}$ presentation signaled a minimum $30-\mathrm{sec}$ wait before the delivery of the next food. Sessions were 20-min long In this way, $\mathrm{N}$ was initially trained as a predictor of nonreinforcement.

For the main training phase of this study, the birds were divided into two groups on the basis of rates of responding in a previous study. On each day, all birds received a 20 -min random training session containing 1210 -sec presentations of $X$, three of which terminated in reinforcement. In addition, 17 unsignaled foods also occurred. Training schedules were constructed as described in Experiment 1 . For half the birds, the $\mathrm{N}$ stimulus occurred throughout the training session except during 10 -sec periods preceding each unsignaled food and during the 10-sec keylight. This is the same schedule as that employed by Goddard and Jenkins. The other half of the birds received the same schedule, except that the $\mathrm{N}$ stimulus terminated $10 \mathrm{sec}$ earlier in all cases. In other words, extra USs were signaled by a 20 -sec $\mathrm{N}$-off period, and the $\mathrm{N}$-off period began 10 sec prior to each CS and then extended throughout the CS presentation. Training proceeded for $\mathbf{4 8}$ days.

Following this training, the birds were switched to a new schedule in which the $\mathrm{N}$ stimulus was now allowed to continue throughout the CS presentations. In other words, $\mathrm{N}$-off periods now occurred only prior to the 17 extra US presentations. The $\mathrm{N}$-off duration remained as before. Training was carried out for $\mathbf{4 8}$ days.

Finally, the birds were switched back to the original training schedule, in which the white noise terminated both prior to the extra USs and cluring the CS trials. This training occurred for 12 days.

\section{Results and Discussion}

Figure 3 depicts responding to the $\mathrm{X}$ keylight over blocks of 4 days for the three training phases of Experiment 2. Data from all animals were combined, since stimulus duration did not produce differences in Phase 1 $[U(8,8)=31.5, p>.05]$, Phase $2[U(8,8)=17$, $p>.05]$, or Phase $3[U(8,8)=19.5, p>.05]$ of the study. As is shown in the left-hand portion of Figure 3, there was little evidence for acquisition in the first training phase. On the last block of training, only 7 of 16 birds emitted any responses. Responding actually declined over the course of training. The birds pecked on $40 \%$ of all trials over the first 2 days of training (possibly as a result

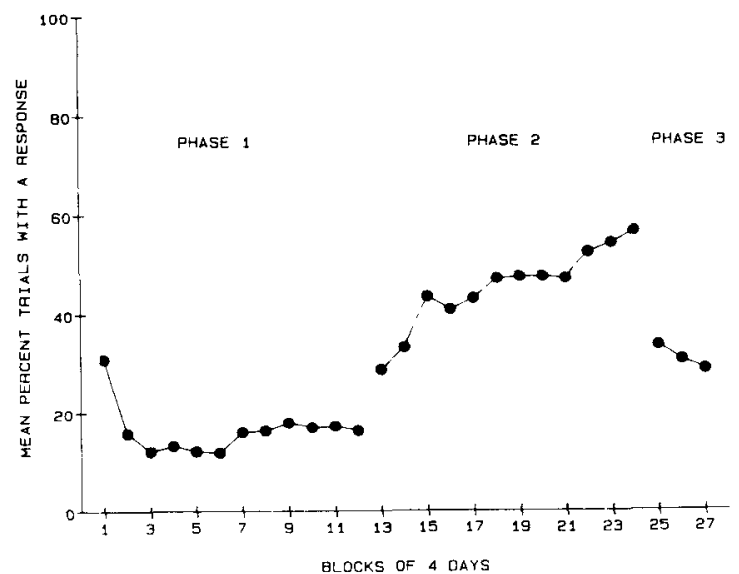

Figure 3. Mean percent of trials with a response during the three training phases of Experiment 2. of generalization from stimuli used in other studies) but on only $16 \%$ of trials over the last 2 days $[T(15)=19$, $p<.05]$. This level of responding is comparable to that commonly seen during unsignaled random training (e.g., see Goddard \& Jenkins, 1987, Experiment 1).

The low levels of responding in Phase 1 are further highlighted by the results of Phase 2, during which the noise-off stimulus was prevented from occurring during $X$ keylight trials. Under these conditions, substantial responding to the keylight developed. On the first block of Phase 2 training, the birds already responded reliably more than on the last block of training in Phase 1 $[T(7)=0, p<.05]$. This difference continued to grow throughout Phase 2 training, and it was highly reliable on the last block of training $[T(11)=0, p<.01]$.

The transition back to the original training schedule caused responding to drop off rapidly. The birds pecked on fewer trials on the first block of Phase 3 than on the last block of Phase $2[T(12)=4, p<.01]$. This difference was still evident on the last block of Phase 3 $[T(11)=0, p<.01]$.

These results are therefore inconsistent with the findings of Goddard and Jenkins (1987), who reported response acquisition using the Phase 1 training schedule employed here. The present study failed to demonstrate acquisition with either Goddard and Jenkins' training parameters or a longer noise-off stimulus. The results of Phase 2, however, demonstrate that the failure to obtain acquisition in the first phase was not the result of using inadequate stimuli. When the noise-free period was used to signal only extra USs, reliable acquisition occurred. As soon as the noise-off stimulus was again presented together with the keylight in Phase 3, however, responding rapidly declined. These results suggest that providing a period of signaled nonreinforcement is not the crucial variable in promoting responding to a target $C S$ when extra USs are signaled in a random training procedure. Rather, it appears that the critical factor is prevention of the background from competing with the CS for associative strength during training.

\section{GENERAL DISCUSSION}

Taken as a whole, the results of the two studies reported here do little to encourage the view that responding to randomly trained CSs will develop if contrasting periods of signaled nonreinforcement are provided. In Experiment 1 , the most general form of this theory was tested with discrete 10-sec signals of nonreinforcement during the ITI of a random training schedule. No responding to the target CS was observed. In Experiment 2, we elaborated on this result by providing a signal throughout nonreinforced periods of the ITI and further failing to find any evidence of acquisition of responding to the target $\mathrm{CS}$. When the signal for nonreinforcement was partially compromised by being presented in compound with the reinforced $C S$, responding developed. When the signal for nonreinforcement and the CS were separated, respond- 
ing again declined. These results are the opposite of those predicted by the signaled nonreinforcement view advanced by Goddard and Jenkins (1987), but they are fully consistent with the predictions of a competition model of learning such as that of Rescorla and Wagner (1972).

In Experiment 1, for example, a competition model of learning predicts that no responding should develop for the birds receiving the discrete signal of nonreinforcement, since such a signal does not prevent the background from becoming conditioned and blocking learning about the target CS. In fact, such a signal of nonreinforcement should help prevent contextual extinction and thereby further attenuate responding to the target. Floor effects prevent a fair evaluation of this prediction, but the nonreliable trend toward more responding in Group Unsignaled than in Group Unpaired (shown in Figure 1) is consistent with this suggestion.

The results of Experiment 2 are similarly predicted by competition models of learning. In Phase 1 , no responding to the keylight would be expected to develop, since the noise-off stimulus should acquire substantial associative strength from signaling the extra USs and should thereby block acquisition of responding to the target CS. In Phase 2, the noise-off blocker is removed from the CS and acquisition should result. When the noise-off stimulus is returned during the CS in Phase 3, the schedule is now one in which two already well-trained CSs are placed in compound and followed by the same US as was used in training. Such a situation should produce "overexpectation" of the US (e.g., see Kremer, 1978; Rescorla, 1972) and subsequent loss of responding. This predicted pattern was precisely the one observed.

A recent, elegant experiment by Durlach (in press) has further confirmed these observations in a between-subjects design. In her study, Durlach gave six groups of birds experience with a random training schedule in which a signal was provided before all ITI USs (signaled condition), both before the ITI USs and in compound with the target CS (blocking condition), or not at all (unsignaled condition). For half the birds, the signal was a 10 -sec auditory stimulus, while for the other half, the signal was a 10-sec omission of the auditory stimulus that otherwise remained on. The birds responded reliably more in the two signaled conditions than in the blocking or unsignaled conditions. Furthermore, there were no differences between groups as a function of whether the presence or absence of the auditory stimulus was used as the signal. Like the present results, these findings suggest that preventing competition from background cues is the crucial factor in generating CS responding on a random schedule.

It should be noted that the results obtained here are similar in many ways to those obtained in a CER study discussed by Rescorla (1972). In that experiment, several groups of rats were given uncorrelated presentations of a tone and shock. For one group of animals, all shocks not preceded by a tone were signaled by a clicker. For a second group, the clicker signaled all shocks regard- less of whether they were preceded by the tone. A third group received clicker presentations randomly throughout the session. Fear of the tone developed in the first group, but not in the other two. As in the present study, responding to the target CS failed to develop whenever it was reinforced in the presence of a more excitatory stimulus (the clicker in Group 2 and the context in Group 3).

Although the present results favor the notion that signaling ITI USs in a random schedule promotes conditioned responding through blocking of the context, the results of Jenkins and Lambos (1983) and Brandon (1984) support that view less. Both reports suggest that the signaling of ITI USs is not sufficient to prevent the response loss seen when an excitatory CS is placed in a random schedule. When ITI USs were signaled without setting up contrast periods of signaled nonreinforcement, rapid response loss occurred. The discrepancy between those data and the results reported here may reflect the consequences of giving random training to an already excitatory CS rather than to a novel stimulus. Some authors (e.g. , Rescorla, in press; Robbins, 1988) have suggested, for example, that random training prevents learning about a novel CS, but serves only to reduce performance to a $\mathrm{CS}$ given prior excitatory training. When responding to a novel CS trained on a random schedule fails to develop, that performance deficit persists through extinction testing outside the context of training (e.g., see Durlach, 1983). However, when previously conditioned responding is reduced through application of a random schedule, robust recovery of that responding is seen during an extinction test (e.g., see Lindblom \& Jenkins, 1981). The effects of signaling ITI USs during random training may similarly differ as a function of the prior value of the target CS.

One issue left unresolved here concerns why Goddard and Jenkins (1987) observed substantial acquisition using a procedure found to generate little responding in the present Experiment 2. It is possible that differences in the salience of the auditory stimulus contributed to these differential outcomes. If the tone-off signal used by Goddard and Jenkins were of low salience, it might have successfully prevented conditioning of a less salient background but not of a more salient keylight CS. Other investigators (e.g., Hall, Mackintosh, Goodall, \& Dal Martello, 1977) have found evidence that a well-trained stimulus of low salience may fail to block fully a neutral stimulus of higher salience. However, any account based on the simple ordering of saliences of background, auditory stimulus, and keylight CS also seems incorrectly to imply that the background would be incapable of blocking conditioning to the $\mathrm{CS}$ in a conventional random schedule. Furthermore, such an account fails to explain why Durlach (in press) did not replicate the results of Goddard and Jenkins, despite using a tone stimulus similar to theirs as a signal of nonreinforcement.

Whatever the cause of the discrepancy, however, the implications of the data obtained here are quite straight- 
forward. Little evidence was found to support the notion that signaling extra USs in a random schedule promotes responding to the target $\mathrm{CS}$ due to the consequent establishment of periods of signaled nonreinforcement. Instead, both studies reported here indicate that preventing contextual cues from competing with the target CS for associative strength is the necessary condition for promoting responding on a schedule of random CS and US presentations.

\section{REFERENCES}

Ayres, J. J. B., Benedict, J. O., \& Witcher, E. S. (1975). Systematic manipulation of individual events in a truly random control in rats. Joumal of Comparative \& Physiological Psychology, 88, 97-103.

Brandon, S. E. (1984). A test of the Wagner-Rescorla model's prediction of no response decrement in a nondifferential following a differential schedule of reinforcement. Animal Learning \& Behavior, 12, 137-141.

DuRLaCH, P. J. (1983). Effect of signaling intertrial unconditioned stimuli in autoshaping. Journal of Experimental Psychology: Animal Behavior Processes, 9, 374-389.

DURLACH, P. J. (in press). The role of signals for US absence in the sensitivity of autoshaping to contingency. Joumal of Experimental Psychology: Animal Behavior Processes.

DWECK, C. S., \& WAGNER, A. R. (1970). Situational cues and correlation between CS and US as determinants of the conditioned emotional response. Psychonomic Science, 18, 145-147.

GamzU, E. R., \& Williams, D. R. (1973). Associative factors underlying the pigeon's key pecking in autoshaping. Journal of the Experimental Analysis of Behavior, 19, 225-232.

GibBon, J., \& BALSAM, P. (1981). Spreading associatıon in time. In C. M. Locurto, H. S. Terrace, \& J. Gibbon (Eds.), Autoshaping and conditioning theory (pp. 219-253). New York: Academic Press.

GODDARD, M. J., \& JENKINS, H. M. (1987). Effect of signaling extra unconditioned stimuli on autoshaping. Animal Learning \& Behavior, $15,40-46$.

hall, G., Mackintosh, N. J., Goodall, G., \& Dal Martello, M. (1977). Loss of control by a less valid or by a less salient stimulus compounded with a better predictor of reinforcement. Learning \& Motivation, 8, 145-158.
Jenkins, H. M., Barnes, R. A., \& Barrera, F. J. (1981). Why autoshaping depends on trial spacing. In C. M. Locurto, H. S. Terrace, $\&$ J. Gibbon (Eds.), Autoshaping and conditioning theory (pp. 255284). New York: Academic Press.

Jenkins, H. M., \& Lambos, W. A. (1983). Tests of two explanations of response elimination by noncontingent reinforcement. Animal Leaming \& Behavior, 11, 302-308.

KREMER, E. F. (1978). The Rescorla-Wagner model: Losses of associatuve strength in compound conditioned stimuli. Joumal of Experimental Psychology: Animal Behavior Processes, 4, 22-36.

LindBlom, L. L., \& JenKins, H. M. (1981). Responses eliminated by noncontingent or negatively contingent reinforcement recover in extinction. Journal of Experimental Psychology: Animal Behavior Processes, 7, 175-190.

Mackintosh, N. J. (1975). A theory of attention: Variation in the associability of stimuli with reinforcement. Psychological Review, 82, 276-298.

Miller, R. R., \& Schachtman, T. R. (1985). Conditioning context as an associative baseline: Implication for response generation and the nature of conditioned inhibition. In R. R. Miller \& N. E. Spear (Eds.), Information processing in animals: Conditioned inhibition (pp. 51-88). Hillside, NJ: Erlbaum.

Rescorla, R. A. (1968). Probability of shock in the presence and absence of the CS in fear conditioning. Journal of Comparative \& Physiological Psychology, 66, 1-5.

ResCoRLA, R. A. (1972). Informational variables in Pavlovian conditioning. In G. H. Bower (Ed.), The psychology of learning and motivation (Vol. 6, pp. 1-46). New York: Academic Press.

RESCORLA, R. A. (in press). Redundant treatments of neutral and excitatory stimuli in autoshaping. Journal of Experimental Psychology: Animal Behavior Processes.

Rescorla, R. A., \& WAGNer, A. R. (1972). A theory of Pavlovian conditioning: Variations in the effectiveness of reinforcement and nonreinforcement. In A. H. Black \& W. F. Prokasky (Eds.), Classical conditioning II: Current theory and research (pp. 64-99). New York: Appleton-Century-Crofts.

RoBBINS, S. J. (1988). Role of context in performance on a random schedule in autoshaping. Joumal of Experimental Psychology: Animal Behavior Processes, 14, 413-424.

(Manuscript received August 15, 1988; revision accepted for publication January $5,1989$. .) 